\title{
Phenotypic and molecular characterization of apple (Malus $\times$ domestica Borkh) genetic resources in Greece
}

\author{
Ioannis Ganopoulos ${ }^{1}$, Nikolaos Tourvas², Aliki Xanthopoulou ${ }^{3}$, Filippos A. Aravanopoulos², Euaggelia Avramidou², Antonios Zambounis ${ }^{4}$, \\ Athanasios Tsaftaris ${ }^{5}$, Panagiotis Madesis ${ }^{3}$, Thomas Sotiropoulos ${ }^{4 *}$, Nikolaos Koutinas ${ }^{6}$
}

\author{
${ }^{1}$ Hellenic Agricultural Organization/Institute of Plant Breeding \\ and Genetic Resources - 57001 - Thermi - Thessaloniki - \\ Greece. \\ ${ }^{2}$ Aristotle University of Thessaloniki/Faculty of Forestry and \\ Natural Environment - Dept. of Forest Genetics and Tree \\ Breeding, University Campus - 54124 - Thessaloniki - \\ Greece. \\ ${ }^{3}$ Center for Research and Technology Hellas/nnstitute of \\ Applied Biosciences, P.O. Box 60361 - 57001 - Thermi - \\ Thessaloniki - Greece. \\ ${ }^{4}$ Hellenic Agricultural Organization/nstitute of Plant Breeding \\ and Genetic Resources - Dept. of Deciduous Fruit Growing \\ in Naoussa, RR Station 38 - 59035 - Naoussa - Greece. \\ ${ }^{5}$ American Farm School - Perrotis College, GR-57001 - \\ Thessaloniki - Greece. \\ ${ }^{6}$ Alexander Technological Educational Institute of \\ Thessaloniki/School of Agricultural Technology, Food \\ Technology and Nutrition, P.O. Box 141 - $57400-$ \\ Thessaloniki - Greece. \\ ${ }^{*}$ Corresponding author <thosotir@otenet.gr>
}

Edited by: Leonardo Oliveira Medici

Received December 20, 2016

Accepted September 07, 2017

\section{Introduction}

Malus $\times$ domestica Borkh. (apple) is the crop with the highest economic impact of the Rosaceae family (FAO, 2015) and among the most important fruit crops of temperate zones. Traditionally, genetic diversity in apple species or varieties was assessed with morphological descriptors (Reig et al., 2015), commonly produced by the International Board for Plant Genetic Resources (IBPGR, 1983) and later by the International Union for the Protection of New Varieties of Plants (UPOV, 2005). The multivariate data analysis is an efficient approach to analyze large data of apple qualitative phenotypic traits and is considered the most suitable to identify patterns and relationships among powerful statistical techniques, such as the principal component analysis (PCA) and the cluster analysis (Oliveira et al., 2012; Furones-Pérez and Fernández-López, 2009; Ganopoulos et al., 2015; Mehmood et al., 2014).

However, the use of molecular markers to identify the genetic makeup of a species and a variety has become one of the most important means to characterize and manage germplasm collections of fruit species
(Fernández-Fernández, 2010). Microsatellites, or SSRs, are the DNA markers of choice to uncover the genetic diversity between and within fruit species /Gupta et al., 1996), due to their high polymorphism level, abundance and co-dominant inheritance and reproducibility, as well as relative easiness of analysis (Madesis et al., 2013). Previously, many authors used this technique to determine the genetic diversity in order to identify duplicates and genetic relationships within and between Malus $\times$ domestica accessions (Garkava-Gustavsson et al., 2013; Gaši et al., 2010; Lassois et al., 2015; Liang et al., 2015; Oraguzie et al., 2005; Patzak et al., 2012; Pina et al., 2014; Urrestarazu et al., 2012). Nevertheless, only a few reports have demonstrated basic and detailed data on adaptability and fruit quality traits of Malus $\times$ domestica cultivars from different geographical areas, especially from species grown under the Greek climatic conditions.

Hence, this work aimed to: (1) determine the variability of different accessions based on phenotypic and fruit quality traits under the south-eastern Mediterranean basin climatic conditions, (2) identify the most important sources of variability of all accessions analyzed 
and the associations between the traits evaluated, (3) fingerprint and characterize the Greek germplasm collection using microsatellite markers of five Greek and 14 international cultivars respectively, (4) investigate the relationships among cultivars based on their genetic and phenotypic distances, and finally (5) provide useful information for breeders to select local Greek varieties of Malus $\times$ domestica for breeding programs, or for producers aiming to diversify apple production.

\section{Materials and Methods}

\section{Plant material}

We evaluated 19 cultivars (Malus $\times$ domestica Borkh) from the apple germplasm collection in Naoussa, Central Macedonia, Greece (40³7'13.8" N 22 $06^{\prime} 49.2^{\prime \prime}$ E, elevation: $130 \mathrm{~m}$ ) (Table 1).

\section{Phenotypic analysis}

Between 2005 and 2010, 47 qualitative traits were evaluated following the established descriptor lists and scores (IPGRI, 1982; UPOV, 2005): Plant: Vigor: 3: weak 5: medium 7: strong (PV), Plant: Type, 1: columnar 2: ramified (PT), Plant: Habit (columnar types excluded), 1: fastigiated 3: upright 5: spreading 7: drooping 9: weeping (PH), Plant: Type of bearing, 1: on spurs 2: on spurs and long shoots 3: on long shoots (PTB), Dormant one-yearold shoot: Pubescence (on upper half of shoot), 1: absent or very weak 3: weak 5: medium 7: strong 9: very strong (DSP), Dormant one-year-old shoot: Thickness (diameter at centre), 3: thin 5: medium 7: thick (DST), Dormant one-year-old shoot: Length of internode, 1: very short 3: short 5: medium 7: long 9: very long (DSLI), Dormant one-year-old shoot: Number of lenticels, 3: few 5: medium 7: many (DSNL), Unopened flower: Colour (balloon stage), 1: white 2: yellowish and pink 3: light pink 4: dark pink 5: red 6: purple (UFC), Flower: Size (diameter of flower with petals pressed into horizontal position), 3: small 5: medium 7: large (FS), Flower: Arrangement of petals, 1: free 2: touching 3: overlapping (FAP), Leaf: Attitude in relation to shoot, 3: upwards 5: outwards 7: downwards (LAS), Leaf blade: Length, 3: short 5: medium 7: long (LBL), Leaf blade: Width, 3: narrow 5: medium 7: large (LBW), Leaf blade: Ratio length/ width, 3: small 5: medium 7: large (LBW/L), Leaf blade: Shape of incisions of margin, 1: crenate, 2: serrate, Petiole: Length, 3: short 5: medium 7: long (PL), Fruit: Size, 1: very small 2: very small to small 3: small 4: small to medium 5: medium 6: medium to large 7: large 8: large to very large 9: very large (FS), Fruit: Height/ width ratio, 1: very small 3: small 5: medium 7: large 9: very large (FH/W), Fruit: Shape, 1: globose 2: globose to conical 3: broad globose conical 4: flat 5: flat globose 6: conical 7: narrow conical 8: truncate conical 9: ellipsoid 10: ellipsoid conical (ovoid) 11: oblong 12: oblong conical (FSh), Fruit: Ribbing, 1: absent or very weak 3: weak 5: medium 7: strong 9: very strong (FR), Fruit: Crowning at calyx end, 1: absent or very weak 3: weak 5: medium 7: strong 9: very strong (FC), Fruit: Aperture of eye, 1: closed 2: partly open 3: fully open (FAE), Fruit: Size of eye, 3: small 5: medium 7: large (FSE), Fruit: Length of sepal, 3: short 5: medium 7: long (FLS), Fruit: Depth of eye basin, 3: shallow 5: medium 7: deep (FDE), Fruit: Width of eye basin, 3: narrow 5: medium 7: broad (FEW), Fruit: Thickness of stalk, 3: thin 5: medium 7: thick (FTS), Fruit: Length of stalk, 1: very short 3: short 5: medium 7: long 9: very long, (FLS) Fruit: Depth of stalk cavity, 3: shallow 5: medium 7: deep (FDS), Fruit: Width of stalk cavity, 3: narrow 5: medium 7: broad (FWS), Fruit: Bloom of skin, 1: absent or very weak 2:

Table 1 - Apple cultivars and their main fruit traits analyzed in this study.

\begin{tabular}{|c|c|c|c|c|c|c|}
\hline Cultivar name & Origin & Pedigree & Fruit size & Over color & Intensity of over color & Fruit shape \\
\hline Delicious & U.S.A. & - & Medium & brown & medium & globose \\
\hline Achilles & Greece & Natural mutation of 'Firiki' & Medium to large & red & light & oblong conical \\
\hline Odysseus & Greece & 'Mutsu' × 'Firiki', Greece & Medium to large & red & light & oblong conical \\
\hline Firiki Piliou & Greece & - & Medium to large & red & light & globose to conical \\
\hline Florina & France & '612-1' × 'Jonathan' & Medium to large & orange & medium & globose to conical \\
\hline Forlady & Italy & 'Forum' × 'Lady Williams' & Medium & red & dark & conical \\
\hline FuJi Kiku 8 & Italy & 'Ralls Janet' × ‘Delicious' & Very large & pink & light & ellipsoid \\
\hline Gala Buckeye & U.S.A. & Kidd's Orange Red' × ‘Golden Delicious' & Medium & orange & light & Flat globose \\
\hline Gala Brookfield & New Zealand & Kidd's Orange Red' × 'Golden Delicious' & Medium & orange & light & Flat globose \\
\hline Gold Chief & Italy & ‘Golden Delicious' × 'Starkcrimson’ & Medium to large & orange & light & globose to conical \\
\hline Golden Reinders & Netherlands & - & Medium & orange & medium & truncate conical \\
\hline Golden Delicious & U.S.A. & - & Medium & orange & medium & truncate conical \\
\hline Mutsu & Japan & 'Golden Delicious × Indo’ & Large & orange & medium & globose \\
\hline Mirto & Greece & ‘Golden Delicious’ \& 'Granny Smith’, & Medium to large & orange & medium & truncate conical \\
\hline Ozark Gold & U.S.A. & Golden Delicious $\times$ (Conrad $\times$ Delicious $)$ & Medium & orange & light & conical \\
\hline Scarlet Spur & U.S.A. & - & Medium to large & red & medium & conical \\
\hline Super Chief & U.S.A. & - & Medium to large & red & medium & conical \\
\hline
\end{tabular}


weak 3: strong (FBS), Fruit: Greasiness of skin, 1: absent or very weak 2: weak 3: strong (FGS), Fruit: Ground colour, 1: yellow 2: whitish yellow 3: green yellow 4: whitish green 5: green (FGC), Fruit: Amount of over colour, 1: absent or very low 3: low 5: medium 7: high 9: very high (FAC), Fruit: Over colour, 1: orange 2: pink 3: red 4: purple 5: brown (FOC), Fruit: Intensity of over colour, 3: light 5: medium 7: dark (FIC), Fruit: Pattern of over colour of skin, 1: only solid flush 2: only striped 3: solid flush with indistinct stripes 4: mottled 5: washed out (faded) 6: equally flushed and striped 7: predominantly striped with indistinct flush (FPC), Fruit: Amount of russet around eye basin, 1: absent or very low 3: low 5: medium 7: high 9: very high (FARE), Fruit: Amount of russet on cheeks, 1: absent or very low 3: low 5: medium 7: high 9: very high (FARC), Fruit: Amount of russet around stalk cavity, 1: absent or very low 3: low 5: medium 7: high 9: very high (FARS), Fruit: Size of lenticels, 3: small 5: medium 7: large (FSL), Fruit: Firmness of the flesh (measurement with penetrometer), 1: very soft 3 : soft 5: medium 7: firm 9: very firm (FFF), Fruit: Colour of the flesh, 1: white 2: cream 3: yellowish 4: pink 5: greenish $(\mathrm{FCF})$, Fruit in cross-section: Aperture of locules (median through locules), 1: closed 2: partly open 3: fully open (FAL), Time of beginning of flowering (10 $\%$ open flowers), 1: very early 3 : early 5 : medium 7 : late 9: very late (TBF), Time of maturity for consumption, 1: very early 3: early 5: medium 7: late 9: very late (TMC), (Table 2). Fruits were handpicked at commercial maturity by a single person to ensure consistency of the maturity grade.

\section{DNA isolation}

In order to isolate total genomic DNA, we used dry leaves collected from all localities via the cetyl trimethylammonium bromide (CTAB), as described in Doyle (1987). Both quality and concentration of the extracted DNA were determined by ultraviolet spectrophotometry.

\section{Microsatellite analysis}

Seven microsatellite markers $(02 \mathrm{~b} 1,28 \mathrm{f} 4,05 \mathrm{~g} 8$, CH01E12, CH01H01, CH01F02, CH01H10) were chosen from the marker sets recommended by the ECPGR for apple germplasm and were used in this study (Guilford et al., 1997; Gianfranceschi et al., 1998). The markers used were selected based on their informativeness. We selected the markers with the highest Polymorphic Information Content (PIC) and heterozygosity (He) values) and the type of their repeat (di-, tri- or more repeat units). Polymerase Chain Reaction (PCR) amplifications were carried out in a reaction volume of $20 \mu \mathrm{L}$ containing $20 \mathrm{ng}$ of template DNA, 10x PCR buffer, $200 \mu \mathrm{M}$ of each dNTP, 10 pmol of each primer (forward primer labelled with FAM, NED, PET and VIC fluorescent dyes) and $1 \mathrm{U}$ of Taq DNA Polymerase. PCR amplifications were performed according to Guilford et al. (1997) and Gianfranceschi et al. (1998). The PCR products obtained were first run in $2 \%$ agarose gel and then loaded into an ABI PRISM $3730 \times 1$ DNA sequencer. The program GENEMAPPER was used to genotype the alleles.

\section{Statistical analysis}

The data on 19 apple cultivars, including 47 qualitative traits, were analyzed by the XLSTAT software (version 2014.1). The Principal Components Analysis (PCA) method was used to investigate the simultaneous contribution of all qualitative traits to order the apple cultivars in multivariate space. We used the correlation matrix, as standardization was necessary since the variables were measured in different units (quantitative and qualitative). In addition, the PCA on the correlation matrix separated size from shape more effectively (Somers, 1986). Within the PCA, if factor loadings were above 0.55 , they were considered significant, since the number of observations was 47 (see also Mehmood et al., 2014). The three most important principle components were used to construct 2D plots for each case to enable visualization of the results. In the correlation analysis, the Spearman coefficient (non-parametric) was used to assess the correlation between qualitative traits. The dendrogam was constructed using the qualitative trait data. The Euclidean distance was chosen to estimate the genetic dissimilarity component and the Ward's method was used for the agglomerative hierarchical clustering (AHC).

The data on microsatellite markers were used to assess the effective number of alleles ( $\mathrm{Ne})$, number of alleles (Na), and expected heterozygosity (He) using POPGEN v.1.32 (Krawczak et al., 2006). PowerMarker 3.25 was used to estimate the Nei's genetic diversity and polymorphism information content (PIC) (Liu and Muse, 2005). The power of discrimination (PD), which estimates the probability that two randomly sampled individuals are discriminated, was evaluated for each locus according to Kloosterman et al. (1993): $\mathrm{PD}=1-\Sigma\left(p_{i}\right)^{2}$ where Pi is the frequency of the $i^{\text {th }}$ genotype. The probability of identity $\left(\mathrm{PI}=1-\sum p i^{4}+\sum \sum\left(2 p_{i} p_{j}\right)\right.$, where $p_{i}$ and $p_{j}$ are the frequency of the $i^{\text {th }}$ and $j^{\text {th }}$ alleles, respectively, calculates the probability that two randomly drawn diploid genotypes are identical assuming observed allele frequencies and random assortment (Paetkau et al., 1995). The total probability of identity, defined as the likelihood of two varieties sharing the same genetic profile by chance, was also calculated from the individual PI values. PI was calculated by IDENTITY 1.0. The UPGMA algorithm was used for dendrogram construction based on similarities between genotypes that were calculated by the Dice's coefficient (Nei and Li, 1979). GENALEX version 6.501 was used for the Principal Coordinate Analysis (PCoA) (Peakall and Smouse, 2012). The analysis was performed in a multidimensional space with data standardization. The Mantel test was performed using GENALEX version 6.501 to identify possible statistical significant correlations between morphological and genetic distances (Peakall and Smouse, 2012). 
Table 2 - List of phenotypic descriptors and their results in 19 apple cultivars analyzed in this study.

\begin{tabular}{|c|c|c|c|c|c|c|c|c|c|c|c|c|c|c|c|c|c|c|c|}
\hline $\begin{array}{l}\text { Phenotypic } \\
\text { traits according } \\
\text { to CPVO TP } \\
14 / 1\end{array}$ & 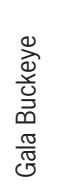 & 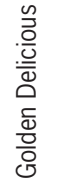 & 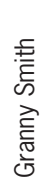 & $\stackrel{\stackrel{0}{\frac{O}{2}}}{\sum}$ & 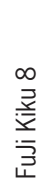 & 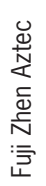 & 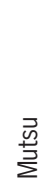 & $\begin{array}{l}\text { 믕 } \\
\text { U } \\
\text { 产 } \\
\text { N }\end{array}$ & $\frac{\mathfrak{0}}{\frac{0}{0}}$ & 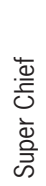 & 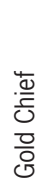 & 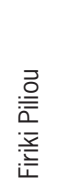 & 希 & 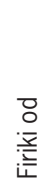 & $\begin{array}{l}\stackrel{0}{\frac{\pi}{5}} \\
\text { 흔 }\end{array}$ & 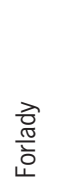 & 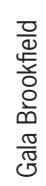 & 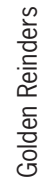 & 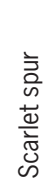 \\
\hline$\overline{\mathrm{PV}}$ & 5 & 5 & 7 & 3 & 7 & 7 & 7 & 3 & 5 & 5 & 5 & 7 & 7 & 7 & 7 & 5 & 5 & 5 & 5 \\
\hline PT & 2 & 2 & 2 & 2 & 2 & 2 & 1 & 1 & 2 & 2 & 1 & 1 & 1 & 1 & 2 & 2 & 2 & 2 & 2 \\
\hline PH & 5 & 3 & 5 & 5 & 5 & 5 & 3 & 3 & 5 & 3 & 3 & 3 & 3 & 3 & 5 & 5 & 5 & 3 & 3 \\
\hline PTB & 2 & 2 & 2 & 2 & 2 & 2 & 2 & 2 & 2 & 1 & 2 & 2 & 2 & 2 & 1 & 2 & 2 & 2 & 1 \\
\hline DSP & 3 & 1 & 1 & 1 & 5 & 5 & 3 & 5 & 5 & 5 & 3 & 1 & 1 & 1 & 5 & 7 & 3 & 1 & 5 \\
\hline DST & 5 & 5 & 5 & 5 & 7 & 7 & 7 & 5 & 5 & 5 & 5 & 3 & 3 & 3 & 5 & 7 & 5 & 5 & 5 \\
\hline DSLI & 5 & 7 & 5 & 5 & 7 & 7 & 7 & 3 & 3 & 3 & 3 & 5 & 5 & 5 & 7 & 7 & 5 & 7 & 3 \\
\hline DSNL & 3 & 5 & 3 & 3 & 5 & 5 & 3 & 7 & 7 & 5 & 7 & 3 & 5 & 5 & 3 & 5 & 3 & 5 & 5 \\
\hline UFC & 3 & 3 & 4 & 4 & 4 & 4 & 5 & 5 & 6 & 4 & 5 & 4 & 5 & 5 & 3 & 3 & 3 & 3 & 4 \\
\hline FS & 7 & 7 & 7 & 7 & 7 & 7 & 7 & 3 & 5 & 5 & 7 & 5 & 5 & 5 & 5 & 5 & 7 & 7 & 5 \\
\hline FAP & 1 & 2 & 2 & 2 & 2 & 2 & 2 & 1 & 2 & 1 & 2 & 1 & 1 & 1 & 2 & 3 & 1 & 2 & 1 \\
\hline LAS & 3 & 3 & 7 & 7 & 5 & 5 & 3 & 3 & 3 & 3 & 3 & 3 & 3 & 3 & 3 & 3 & 3 & 3 & 3 \\
\hline LBL & 5 & 5 & 7 & 7 & 7 & 7 & 7 & 3 & 5 & 5 & 5 & 5 & 5 & 5 & 5 & 5 & 5 & 5 & 5 \\
\hline LBW & 7 & 7 & 7 & 7 & 7 & 7 & 7 & 7 & 5 & 5 & 7 & 3 & 3 & 3 & 5 & 7 & 7 & 7 & 5 \\
\hline LBW/L & 7 & 5 & 7 & 7 & 5 & 5 & 3 & 7 & 7 & 7 & 5 & 3 & 3 & 3 & 5 & 7 & 7 & 5 & 7 \\
\hline LBS & 1 & 1 & 1 & 1 & 1 & 1 & 1 & 1 & 1 & 1 & 1 & 1 & 1 & 1 & 1 & 1 & 1 & 1 & 1 \\
\hline $\mathrm{PL}$ & 7 & 5 & 5 & 5 & 7 & 7 & 3 & 5 & 5 & 5 & 5 & 7 & 7 & 7 & 7 & 7 & 7 & 5 & 5 \\
\hline FS & 5 & 5 & 6 & 6 & 9 & 9 & 7 & 5 & 6 & 6 & 6 & 5 & 6 & 6 & 6 & 5 & 5 & 5 & 6 \\
\hline $\mathrm{FH} / \mathrm{W}$ & 3 & 5 & 3 & 3 & 5 & 5 & 5 & 3 & 5 & 3 & 5 & 9 & 9 & 9 & 5 & 5 & 3 & 5 & 3 \\
\hline FSh & 5 & 8 & 8 & 8 & 9 & 9 & 1 & 6 & 1 & 6 & 2 & 2 & 12 & 12 & 2 & 6 & 5 & 8 & 6 \\
\hline FR & 3 & 1 & 1 & 1 & 7 & 1 & 1 & 1 & 3 & 1 & 1 & 3 & 3 & 3 & 1 & 1 & 3 & 1 & 1 \\
\hline $\mathrm{FC}$ & 5 & 3 & 5 & 5 & 3 & 3 & 3 & 5 & 5 & 5 & 3 & 3 & 3 & 3 & 1 & 3 & 5 & 3 & 5 \\
\hline FAE & 2 & 1 & 1 & 1 & 3 & 3 & 2 & 1 & 2 & 3 & 2 & 2 & 2 & 2 & 3 & 3 & 2 & 1 & 3 \\
\hline FSE & 5 & 3 & 5 & 5 & 7 & 7 & 5 & 5 & 5 & 7 & 5 & 5 & 5 & 5 & 5 & 7 & 5 & 3 & 7 \\
\hline FLS & 5 & 3 & 5 & 5 & 5 & 5 & 5 & 5 & 5 & 7 & 3 & 3 & 3 & 3 & 5 & 5 & 5 & 3 & 7 \\
\hline FDE & 5 & 5 & 5 & 5 & 5 & 5 & 7 & 5 & 5 & 5 & 5 & 5 & 5 & 5 & 7 & 7 & 5 & 5 & 5 \\
\hline FWE & 5 & 3 & 5 & 5 & 5 & 5 & 7 & 5 & 5 & 5 & 3 & 5 & 5 & 5 & 5 & 7 & 5 & 3 & 5 \\
\hline FTS & 5 & 5 & 5 & 5 & 7 & 7 & 5 & 7 & 7 & 7 & 5 & 5 & 5 & 5 & 5 & 5 & 5 & 5 & 7 \\
\hline FLS & 5 & 5 & 7 & 7 & 5 & 5 & 5 & 1 & 3 & 3 & 5 & 1 & 1 & 1 & 3 & 3 & 5 & 5 & 3 \\
\hline FDS & 7 & 3 & 3 & 3 & 5 & 5 & 7 & 5 & 5 & 5 & 3 & 5 & 5 & 5 & 7 & 5 & 7 & 3 & 5 \\
\hline FWS & 5 & 5 & 5 & 5 & 5 & 5 & 7 & 5 & 5 & 7 & 5 & 3 & 3 & 3 & 5 & 5 & 5 & 5 & 7 \\
\hline FBS & 1 & 1 & 1 & 1 & 2 & 2 & 1 & 1 & 1 & 1 & 1 & 1 & 1 & 1 & 2 & 2 & 1 & 1 & 1 \\
\hline FGS & 1 & 1 & 1 & 1 & 2 & 2 & 1 & 2 & 1 & 1 & 1 & 1 & 1 & 1 & 2 & 2 & 1 & 1 & 1 \\
\hline FGC & 3 & 2 & 5 & 5 & 4 & 4 & 5 & 3 & 3 & 3 & 2 & 3 & 3 & 3 & 1 & 1 & 3 & 2 & 3 \\
\hline FAC & 7 & 3 & 1 & 1 & 3 & 7 & 1 & 3 & 5 & 9 & 3 & 7 & 7 & 7 & 5 & 7 & 7 & 3 & 9 \\
\hline FOC & 1 & 1 & 1 & 1 & 2 & 3 & 1 & 1 & 5 & 3 & 1 & 3 & 3 & 3 & 1 & 3 & 1 & 1 & 3 \\
\hline FIC & 3 & 5 & 5 & 5 & 3 & 7 & 5 & 3 & 5 & 5 & 3 & 3 & 3 & 3 & 5 & 7 & 3 & 5 & 5 \\
\hline FPC & 6 & 1 & 1 & 1 & 2 & 1 & 1 & 6 & 6 & 3 & 1 & 2 & 2 & 2 & 3 & 1 & 6 & 1 & 3 \\
\hline FARE & 1 & 3 & 1 & 1 & 3 & 3 & 1 & 3 & 3 & 1 & 3 & 3 & 3 & 3 & 5 & 1 & 1 & 3 & 1 \\
\hline FARC & 1 & 3 & 1 & 1 & 1 & 1 & 1 & 3 & 1 & 1 & 3 & 1 & 1 & 1 & 3 & 1 & 1 & 3 & 1 \\
\hline FARS & 3 & 3 & 1 & 1 & 3 & 3 & 1 & 3 & 3 & 1 & 3 & 1 & 1 & 1 & 7 & 3 & 3 & 3 & 1 \\
\hline $\mathrm{FSL}$ & 3 & 5 & 3 & 3 & 5 & 5 & 3 & 5 & 5 & 3 & 5 & 3 & 3 & 3 & 5 & 3 & 3 & 5 & 3 \\
\hline FFF & 5 & 7 & 7 & 7 & 9 & 9 & 7 & 5 & 7 & 7 & 5 & 7 & 7 & 7 & 5 & 7 & 5 & 7 & 7 \\
\hline FCF & 3 & 3 & 1 & 1 & 2 & 2 & 1 & 3 & 3 & 1 & 3 & 1 & 1 & 1 & 3 & 2 & 3 & 3 & 1 \\
\hline FAL & 2 & 2 & 2 & 2 & 2 & 2 & 2 & 2 & 2 & 2 & 2 & 1 & 1 & 1 & 2 & 2 & 2 & 2 & 2 \\
\hline TBF & 7 & 3 & 7 & 7 & 5 & 5 & 3 & 3 & 7 & 5 & 3 & 7 & 7 & 7 & 3 & 5 & 7 & 3 & 5 \\
\hline TMC & 5 & 5 & 7 & 7 & 9 & 9 & 5 & 5 & 7 & 5 & 5 & 7 & 7 & 7 & 5 & 7 & 5 & 5 & 5 \\
\hline
\end{tabular}

\section{Results and Discussion}

Phenotypic traits of the cultivars

The most important qualitative traits are shown in Table 1. Morphological diversity was observed based on the qualitative trait shape as defined by UPOV. The fruit shape was predominantly conical ('Forlady', 'Ozark
Gold', 'Scarlet Spur', and 'Super Chief'), although other shapes were observed, such as ellipsoid ('FuJi Zhen Aztec', 'FuJi Kiku 8') and globose ('Delicious' and 'Mut$\mathrm{su}^{\prime}$ ). The main over color observed was orange ('Gala Buckeye', 'Gala', 'Brookfield', 'Gold Chief', 'Golden Reinders', 'Golden Delicious', 'Granny Smith', 'Mutsu', 'Mirto', 'Ozark Gold' and 'Florina'). Two cultivars had 
hue of over color: 'FuJi Kiku 8' was pink and 'Delicious' was brown.

\section{Correlation of qualitative traits}

All 47 qualitative traits analyzed in this study showed a strong positive linear correlation (data not shown). The most significant positive correlation was between length of stalk and flower size (0.918). In addition, we observed a significant positive correlation between leaf blade length and attitude in relation to shoot (0.805), stalk length and leaf blade width (0.765), eye size and pubescence (0.718), eye aperture and pubescence $(0.716)$ and maturity time for consumption and flesh firmness (0.710). However, significantly high negative correlations between some qualitative traits were observed, including the leaf blade: ratio length/ width and fruit: height/ width ratio $(-0.858)$ as well as fruit ground color and russet amount on cheeks (-0.614). These traits, which showed moderate to high correlations, could be a guide to breeding programs and these germplasm sets could be used to improve certain traits and design efficient breeding programs. Trait correlations are very useful, as breeders could use them to ameliorate simultaneously correlated traits by reducing undesired side effects when the focus is only on one of the correlated traits (Chen and Lübberstedt, 2010).

\section{Multivariate analysis of qualitative variables: PCA and AHC cluster analyses}

The most important traits that were included in our developed database were identified by the PCA analysis, which, in this case, allows the multivariate statistical analysis of a large number of variables (Ganopoulos et al., 2015; Ganopoulos et al., 2011). The initial variables were transformed to a decreased number of uncorrelated ones in order to reduce the data, allowing relationships between the individuals and variables to be sufficiently revealed. The distribution of cultivars upon PC-1 and PC-2 reveals the phenotypic variation between the tested cultivars, showing the magnitude of their dispersion along both axes (Figure 1). Using the Kaiser's criterion ("Eigenvalue" > 1) (Kaiser, 1958), seven significant components were obtained, which explained 85.56 $\%$ of the total variation (Table 2). Eigenvalues measure the amount of variation in the total sample accounted for by each factor. The first component, which accounted for $19.14 \%$ of the total variation, includes the traits of locules departure, thickness of dormant one-year-old shoot and fruit flesh color. The second component, which explained $16.47 \%$ of the total variation, was defined by the russet amount on cheeks, fruit eye size and width of fruit eye basin. The third component, which explained $15.06 \%$ of the total variation, was mainly linked to traits of pattern of fruit skin over color, leaf blade length and length/width ratio of leaf blade. The fourth component accounted for $13.84 \%$ of the total variation, which, in this case, involved fruit skin bloom, fruit skin greasiness and russet amount around the fruit eye basin. The fifth

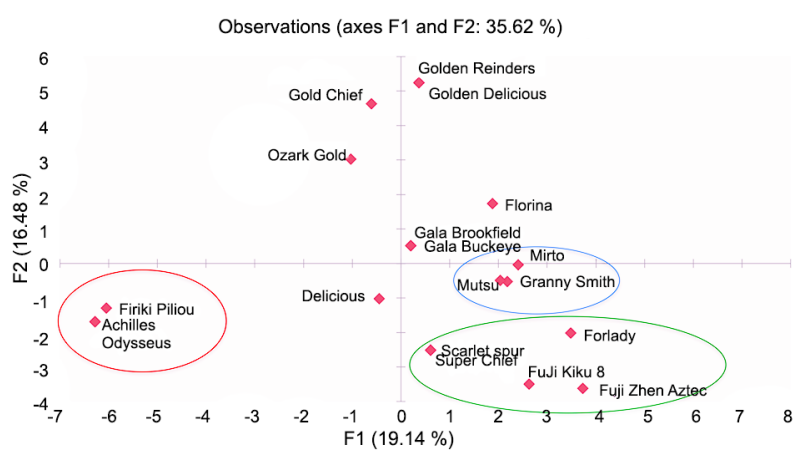

Figure 1 - Two-dimensional PCA plot of the 19 apple cultivars with regard to the first two principal components. Variability explained: F1 (19.14 \%) and F2 (16.48 \%). The first (F1) and second (F2) PCA axes are based on 47 phenotypic covariates.

component clarified $8.47 \%$ of the total variation regarding fruit stalk thickness and depth of fruit stalk cavity. The sixth component explained $7.58 \%$ of the total variation and included plant habit and depth of fruit eye basin. Finally, the seventh component explained $4.97 \%$ of the total variation and included intensity of over fruit color and plant type (Table 3).

In order to preserve an efficient germplasm inventory, its efficient characterization, both phenotypically and genetically, is a prerequisite. In turn, germplasm characterization facilitates the identification of important phenotypic traits. These traits are commonly linked to genetic data and their use is crucial for breeding programs (Ganopoulos et al., 2015; Ganopoulos et al., 2011). Therefore, the clustering analysis and PCA are key tools to group and evaluate cultivars preserved in GeneBank collections (Iezzoni and Pritts, 1991). The multivariate analysis method has been used to study various germplasm collections of Prunus spp. (Ganopoulos et al., 2015; Ganopoulos et al., 2016; Font i Forcada et al., 2014; Khadivi-Khub et al., 2016; Khadivi-Khub et al., 2012; Nikolić et al., 2010; Rakonjac et al., 2010; Ruiz and Egea, 2008) and Malus $\times$ domestica (Gaši et al., 2011; Pereira-Lorenzo et al., 2003; Reig et al., 2015). Here, the PCA testing revealed that all variables examined showed high scores regarding the first eight principal components. The phenotypic traits that were the main sources of variability in the first principal component are the aperture of locules, thickness of dormant one-year-old shoot and fruit flesh color. These results are in agreement with Pereira-Lorenzo et al. (2003), who studied local apple cultivars in northwestern Spain; Gaši et al. (2011), who studied local and foreign apple cultivars in Bosnia-Herzegovina, and Reig et al. (2015), who studied apple phenotypic diversity in the Germplasm bank of the Ebro Valley area in Spain. Thus, the first seven components explained $(85.57 \%)$ of the total variation, which is slightly higher compared with the studies above.

The unsupervised agglomerative hierarchical cluster analysis was used to categorize the data obtained 
Table 3 - First seven components from the PCA analysis of 47 qualitative traits in 19 apple cultivars analyzed.

\begin{tabular}{|c|c|c|c|c|c|c|c|}
\hline Qualitative trait & F1 & F2 & F3 & F4 & F5 & F6 & F7 \\
\hline Plant: Vigor & 0.541 & 2.565 & 4.577 & 1.202 & 0.401 & 1.443 & 0.937 \\
\hline Plant: Type & 5.178 & 0.1 & 0.295 & 0.032 & 1.186 & 2.795 & 9.474 \\
\hline Plant: Habit & 3.659 & 1.094 & 0.114 & 0.013 & 5.976 & 5.489 & 0.327 \\
\hline Plant: Type of bearing & 0.175 & 0.593 & 4.423 & 0.656 & 0.4 & 3.535 & 4.416 \\
\hline Dormant one-year-old shoot: Pubescence & 2.803 & 1.516 & 3.872 & 4.437 & 0.46 & 0.093 & 0.93 \\
\hline Dormant one-year-old shoot: Thickness & 8.659 & 0.265 & 0.147 & 0.638 & 0.106 & 0.146 & 1.604 \\
\hline Dormant one-year-old shoot: Length of internode & 1.426 & 0.021 & 6.078 & 2.154 & 3.157 & 0.969 & 0.724 \\
\hline Dormant one-year-old shoot: Number of lenticels & 0.148 & 0.337 & 0.617 & 1.882 & 13.27 & 3.255 & 0.004 \\
\hline Unopened flower: Colour (balloon stage) & 1.676 & 0.672 & 0.013 & 0.243 & 10.089 & 0.011 & 12.766 \\
\hline Flower: Size & 2.477 & 0.89 & 3.779 & 2.262 & 1.106 & 0.239 & 0.2 \\
\hline Flower: Arrangement of petals & 4.781 & 0.371 & 3.481 & 0.877 & 0.292 & 0.145 & 0.126 \\
\hline Leaf: Attitude in relation to shoot & 2.52 & 1.262 & 3.801 & 2.027 & 0.277 & 3.437 & 0.003 \\
\hline Leaf blade: Length & 2.739 & 2.08 & 5.941 & 1.606 & 0.01 & 0.164 & 0.676 \\
\hline Leaf blade: Width & 6.101 & 2.092 & 0.41 & 0.587 & 0.252 & 0.615 & 1.338 \\
\hline Leaf blade: Ratio length/ width & 2.843 & 0.005 & 5.751 & 1.697 & 0.13 & 3.133 & 0.971 \\
\hline Leaf blade: Shape of incisions of margin & 0 & 0 & 0 & 0 & 0 & 0 & 0 \\
\hline Petiole: Length & 0.75 & 1.847 & 0.308 & 3.295 & 8.773 & 3.689 & 0.576 \\
\hline Fruit: Size & 0.706 & 3.755 & 1.673 & 0.027 & 4.643 & 0.288 & 4.148 \\
\hline Fruit: Height/ width ratio & 3.314 & 0.06 & 4.659 & 4.233 & 0.13 & 0.438 & 0 \\
\hline Fruit: Shape & 0.124 & 0.515 & 2.973 & 0.088 & 0.907 & 3.588 & 7.152 \\
\hline Fruit: Ribbing & 2.805 & 1.476 & 0.091 & 0.018 & 3.291 & 6.23 & 3.794 \\
\hline Fruit: Crowning at calyx end & 0.195 & 0.178 & 4.95 & 7.6 & 0.055 & 2.698 & 0.102 \\
\hline Fruit: Aperture of eye & 0.41 & 5.463 & 0.714 & 4.848 & 0.036 & 0.417 & 0.28 \\
\hline Fruit: Size of eye & 1.167 & 8.114 & 0.826 & 0.63 & 0.7 & 0.043 & 0.127 \\
\hline Fruit: Length of sepal & 3.987 & 3.104 & 4.804 & 0.3 & 0.029 & 0.124 & 0.121 \\
\hline Fruit: Depth of eye basin & 1.258 & 0.062 & 0.03 & 3.179 & 2.066 & 12.717 & 0.802 \\
\hline Fruit: Width of eye basin & 0.327 & 6.178 & 0.156 & 0.019 & 1.685 & 3.703 & 3.431 \\
\hline Fruit: Thickness of stalk & 0.646 & 2.081 & 2.434 & 0.422 & 8.742 & 3.567 & 0.631 \\
\hline Fruit: Length of stalk & 5.252 & 0.705 & 1.905 & 3.588 & 0.472 & 0.24 & 0.011 \\
\hline Fruit: Depth of stalk cavity & 0.008 & 1.797 & 1.99 & 1.45 & 7.256 & 1.437 & 7.968 \\
\hline Fruit: Width of stalk cavity & 5.183 & 0.012 & 2.84 & 0.445 & 1.656 & 4.265 & 0.055 \\
\hline Fruit: Bloom of skin & 2.711 & 1.511 & 0.873 & 7.748 & 0.515 & 0.398 & 0.123 \\
\hline Fruit: Greasiness of skin & 2.022 & 0.42 & 0.022 & 7.499 & 0 & 1.123 & 0.851 \\
\hline Fruit: Ground color & 0.299 & 3.222 & 1.092 & 5.942 & 0.485 & 0.112 & 6.806 \\
\hline Fruit: Amount of over color & 1.263 & 3.017 & 3.547 & 1.06 & 0.571 & 0.073 & 7.052 \\
\hline Fruit: Over color & 1.211 & 6.374 & 0.173 & 1.086 & 2.312 & 0.524 & 2.539 \\
\hline Fruit: Intensity of over color & 4.593 & 0.27 & 0.103 & 0.161 & 1.021 & 2.196 & 8.747 \\
\hline Fruit: Pattern of over color of skin & 0.802 & 0.312 & 8.178 & 0.145 & 1.354 & 2.622 & 3.311 \\
\hline Fruit: Amount of russet around eye basin & 1.323 & 1.069 & 1.193 & 7.032 & 1.333 & 1.823 & 0.547 \\
\hline Fruit: Amount of russet on cheeks & 0.019 & 9.711 & 0.02 & 2.132 & 0.962 & 0.028 & 0.021 \\
\hline Fruit: Amount of russet around stalk cavity & 1.697 & 2.59 & 0.161 & 6.216 & 1.419 & 4.037 & 0.621 \\
\hline Fruit: Size of lenticels & 0.734 & 2.993 & 0.225 & 4.583 & 3.71 & 4.128 & 1.228 \\
\hline Fruit: Firmness of the flesh & 0.245 & 3.955 & 4.135 & 0 & 4.02 & 0.21 & 2.924 \\
\hline Fruit: Color of the flesh & 0.597 & 5.819 & 0.759 & 2.468 & 0.998 & 4.592 & 1.153 \\
\hline Fruit in cross-section: Aperture of locules & 9.101 & 0.927 & 1.144 & 0.045 & 0.128 & 0.086 & 0.203 \\
\hline Time of beginning of flowering & 1.514 & 3.592 & 0.017 & 3.365 & 3.391 & 4.08 & 0.168 \\
\hline Time of maturity for consumption & 0.013 & 5.009 & 4.705 & 0.063 & 0.227 & 5.052 & 0.014 \\
\hline Eigenvalue & 8.997 & 7.745 & 7.081 & 6.508 & 3.982 & 3.56 & 2.33 \\
\hline Variability (\%) & 19.14 & 16.47 & 15.06 & 13.84 & 8.47 & 7.58 & 4.97 \\
\hline Cumulative of variability (\%) & 19.14 & 35.62 & 50.68 & 64.53 & 73.00 & 80.59 & 85.56 \\
\hline
\end{tabular}

in clusters of increasing dissimilarity. The Euclidean distance using the Ward's method for agglomeration was inferred as a metric to estimate the dissimilarity among 19 apple cultivars, based on qualitative data. The relative dendrogram revealed four distinct groups (Figure 2). C1 contained six cultivars ('Gala Buckeye', 'Ozark Gold', 'Delicious', 'Super Chief', 'Gala Brookfield' and 'Scarlet spur'; C2 had six cultivars ('Golden Delicious', 'Mutsu', 'Gold Chief', 'Florina', 'Forlady',
'Golden Reinders'), C3 included four cultivars ('Granny Smith', 'Mirto', 'FuJi Kiku 8' and 'Fuji Zhen Aztec') and C4 contained three cultivars of Firiki group ('Firiki Piliou', 'Achilles' and 'Odysseus'). The maximum distance between the class centroids was observed between $\mathrm{C} 3$ and C4 (12.74), followed by C2 and C4 (12.09), C2 and C3 (8.80) and C1 and C2 (8.34). The dendrogram depicted high diversity between apple cultivars, suggesting that an analyzed germplasm collection could be used in 
breeding programs as a gene pool carrying important genes for contrasting traits. For example, the cultivars of the Firiki group consisting of 'Firiki Piliou', 'Achilles' and 'Odysseus' were highly diversified from other cultivars. This group is characterized by the following major traits: (1) unopened flower color at the bloom station, (2) leaf blade width, (3) amount of over fruit color, (4) fruit stalk length and (5) thickness of dormant one-yearold shoot. These traits are very important, as they affect both yield and quality of apple fruits and thus are the main traits in breeding programs.

The PCA analysis combined with the unsupervised clustering analysis based on phenotypic and fruit quality traits exposed a wide diversity in apple genetic resources in Greece. In turn, this phenotypic diversity between the apple cultivars is of utmost importance for efficient conservation of traditionally grown plant material.

\section{Molecular characterization using microsatellite markers}

The seven microsatellite loci used here amplified 38 alleles (mean 5.42 alleles per locus) showing an average call rate of $99 \%$. The great level of polymorphism, which was presented by the seven microsatellites, supported their ability to be used in the diversity analysis. Primer pair ch01f02 showed the highest number of alleles (8 alleles), whereas primer pair28f4 had the lowest (3 alleles). The number of alleles per locus ranged from 3 to 8 , suggesting moderate molecular genetic diversity between the apple cultivars studied (Ferreira et al., 2016).

PIC values ranged from 0.397 for microsatellite locus $28 \mathrm{f} 4$ to 0.775 for ch01f02 locus, with an average of 0.644 (Table 4). The highest (0.755) and lowest (0.389) expected heterozygosity $(\mathrm{He})$ values were obtained for ch01f02 and 28f4, respectively, with an average of 0.627. The power of discrimination (PD) showed results from $0.38(28 \mathrm{f} 4)$ to 0.86 (ch01f02), with an average of 0.68 . Furthermore, the Shannon's information index (I) maximum (1.620) was recorded for ch01f02, while the lowest value (1.299) was recorded for locus $28 \mathrm{f} 4$, with an average of 1.335. Our results revealed a decreased number of alleles per locus than those reported previously for apple (Gharghani et al., 2009; Liang et al., 2015; Urrestarazu et al., 2012), which could be attributed to the smaller number of cultivars tested in our study. Moreover, the diversity level of heterozygosity in our collection

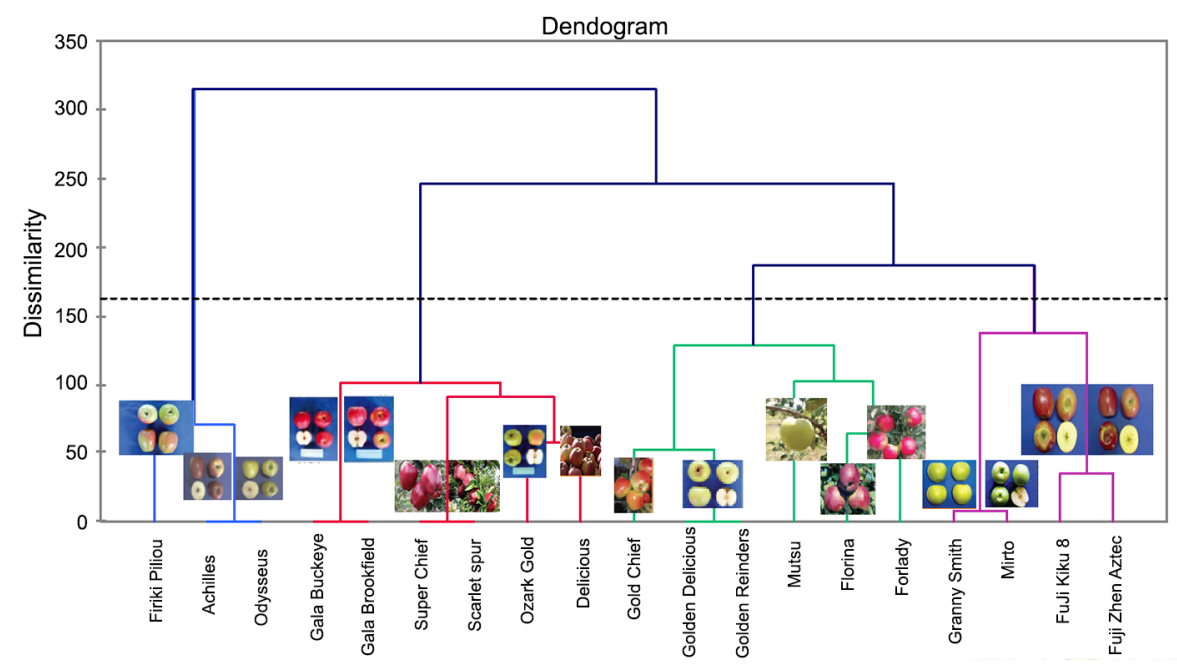

Figure 2 - Dendrogram using agglomerative hierarchical clustering (AHC) for 19 apple cultivars based on 47 qualitative traits.

Table 4 - Genetic diversity parameters for seven polymorphic microsatellites in 19 apple cultivars.

\begin{tabular}{|c|c|c|c|c|c|c|c|c|c|c|c|}
\hline Microsatellite marker & Size range & Species origin & Linkage Group & $\mathrm{Na}$ & $\mathrm{Ne}$ & I & Ho & $\mathrm{He}$ & PIC & PD & $F$ \\
\hline 02b1 & $216-238$ & M. domestica & No position & 6 & 4.011 & 1.505 & 0.789 & 0.751 & 0.771 & 0.81 & -0.052 \\
\hline ch01h01 & $111-129$ & M. domestica & 17 & 6 & 3.099 & 1.343 & 0.684 & 0.677 & 0.696 & 0.76 & -0.010 \\
\hline 05g8 & $111-141$ & M. domestica & No position & 4 & 1.740 & 0.813 & 0.368 & 0.425 & 0.437 & 0.62 & 0.134 \\
\hline ch01f02 & $170-208$ & M. domestica & 12 & 8 & 4.079 & 1.620 & 0.526 & 0.755 & 0.775 & 0.86 & 0.303 \\
\hline ch01e12 & $243-283$ & M. domestica & No position & 6 & 3.374 & 1.450 & 0.684 & 0.704 & 0.723 & 0.74 & 0.028 \\
\hline ch01h10 & $93-117$ & M. domestica & 8 & 5 & 3.282 & 1.321 & 0.947 & 0.695 & 0.714 & 0.63 & -0.363 \\
\hline $28 f 4$ & $106-120$ & M. domestica & No position & 3 & 1.900 & 1.299 & 0.978 & 0.389 & 0.397 & 0.38 & -0.111 \\
\hline Mean & - & - & - & 5.42 & 3.069 & 1.335 & 0.711 & 0.627 & 0.644 & 0.68 & 0.010 \\
\hline
\end{tabular}

$\mathrm{Na}=$ Number of alleles; $\mathrm{Ne}=$ Effective number of alleles; I = Shannon's information index; $\mathrm{Ho}=$ Observed heterozygosity; $\mathrm{He}=$ Expected heterozygosity; PIC = Polymorphism information content; $P D=$ Discrimination power; $F=$ Wright's fixation index. 
(0.627) is slightly lower compared with heterozygosity (0.73) described for apples from the regions of Asturias, the Basque Country, and Galicia in northern and northwestern Spain (Pereira-Lorenzo et al., 2003) and 0.75 in Portuguese apple germplasm collections (Ferreira et al., 2016). In contrast, the diversity observed here was lower than that observed in local cultivars of northeastern Spain (0.82) (Urrestarazu et al., 2012) and 0.80 (Pina et al., 2014), Italy (0.80) (Liang et al., 2015) and Portuguese Azores Islands, (0.81) (Foroni et al., 2012). This result indicates a moderate genetic diversity (Hamrick and Godt, 1996) between the apple germplasm established in a Greek Pomology Institute collection. Possibly, outcrossing and operation of a self- incompatibility system in apple could result in increased levels of heterozygosity and diversity of the cultivars (Mratinić and Akšić, 2012).

The value of the total probability of identity (PI) was low $\left(2 \times 10^{-7}\right)$, showing that the seven microsatellites used were powerful enough to discriminate the apple cultivars used. The apple gene pool examined holds significant genetic diversity and demonstrates differentiation between the four genetic clusters identified by the cluster analysis and the PCoA. The results above show that most apple cultivars examined probably have mixed origin and might share common ancestry.

We constructed a dendrogam of genetic similarity based on the SSR profiles by calculating the Dice coefficient in order to confirm the effectiveness of the seven SSRs to distinguish all cultivars. Indeed, Figure 3 shows that two cultivars were not able to be distinguished (cvs. 'Achilles' and 'Odysseus').

The first two coordinates of the PCoA explained $47.59 \%$ of the total variation in a collection of 19 apple cultivars. The first coordinate explains $26.16 \%$ and the second one explains $21.44 \%$ of the total variation, respectively (Figure 4). The results of the UPGMA method were confirmed by the prediction of unique genotypes on two-dimensional multivariate space. Both the unweighted pair-group method with the arithmetic average dendrograms (UPGMA) and the principal coordinate analysis (PCA) plots showed genetic differentiation between the apple cultivars analyzed.

The Mantel test was used to determine the correlation degree of phenotypic and molecular data. The Mantle tests showed no significant correlation between microsatellite markers with the morphology results. Nonetheless, microsatellite markers were not compatible along the clustering analysis with any of the phenotypic traits, possibly because they are not directly associated with the phenotypic traits analyzed (Kalivas et al., 2016). The PCA and the clustering analysis, using various phenotypic data and in combination with molecular data, showed a wide variability in the apple Germplasm Bank from Naoussa, Central Macedonia, Greece. Accurate knowledge of phenotypic and genetic diversity between cultivars is key for the effective use and conservation of traditional material, which faces a high risk of extinction. Moreover, the data could be used

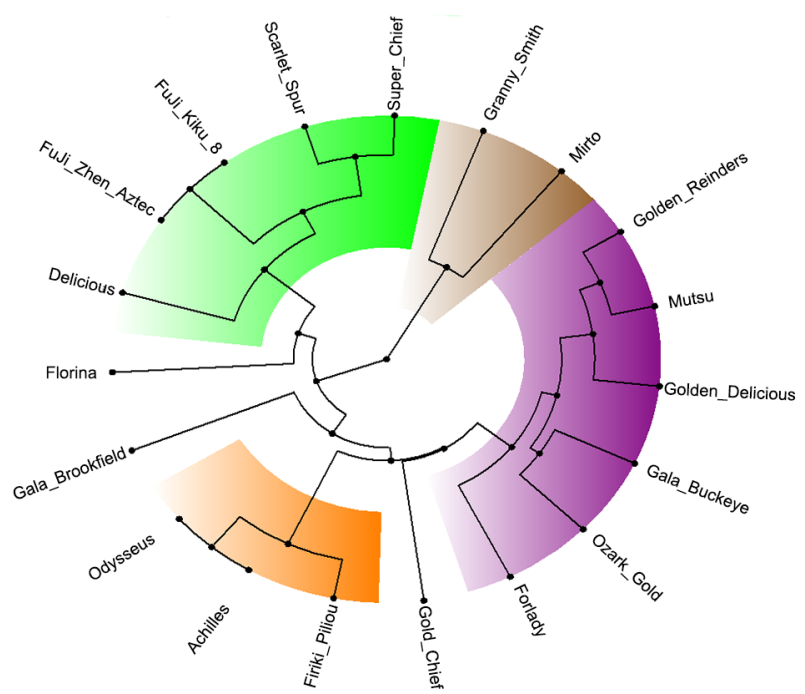

Figure 3 - UPGMA tree showing the genetic relationships between the apple cultivars analyzed in this study.

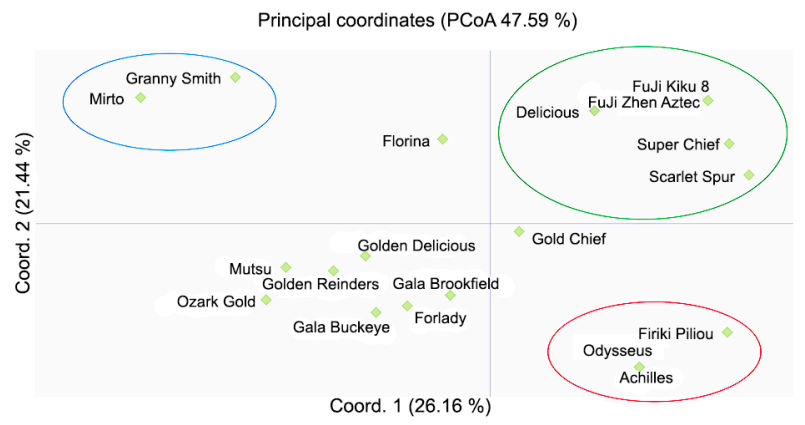

Figure 4 - Principal Coordinate Analysis (PCoA) of the apple cultivars analyzed.

not only for protection, but also in patenting processes of new apple cultivars carried out by the EU-Community Plant Variety Office, such of the PDO cultivar 'Firiki Piliou'. Hence, the cultivars that were comprehensively characterized could be used for gene conservation and for planning an efficient breeding strategy towards favorable apple cultivars with increased adaptation to the Greek climatic conditions and high fruit quality.

\section{References}

Chen, Y.; Lübberstedt, T. 2010. Molecular basis of trait correlations. Trends in Plant Science 15: 454-461.

Fernández-Fernández, F. 2010. Final Report: GC0140 Fingerprinting the National Apple and Pear Collections. Department for Environment Food \& Rural Affairs, London, UK.

Ferreira, V.; Ramos-Cabrer, A.M.; Carnide, V.; Pinto-Carnide, O.; Assunção, A.; Marreiros, A.; Rodrigues, R.; Pereira-Lorenzo, S.; Castro, I. 2016. Genetic pool structure of local apple cultivars from Portugal assessed by microsatellites. Tree Genetics \& Genomes 12: 1-15. 
Font i Forcada, C.; Gradziel, T.M.; Gogorcena, Y.; Moreno, M.Á. 2014. Phenotypic diversity among local Spanish and foreign peach and nectarine [Prunus persica (L.) Batsch] accessions. Euphytica 197: 261-277.

Food and Agriculture Organization of the United Nations [FAO]. 2015. FAOSTAT: Agriculture Data. FAO, Rome, Italy.

Foroni, I.; Baptista, C.; Monteiro, L.; Lopes, M.S.; Mendonça, D.; Melo, M.; Carvalho, C.; Monjardino, P.; Lopes, D.J.H.; Câmara Machado, A.C. 2012. The use of microsatellites to analyze relationships and to decipher homonyms and synonyms in Azorean apples (Malus $\times$ domestica Borkh.). Plant Systematics and Evolution 298: 1297-1313.

Furones-Pérez， P.; Fernández-López， J. 2009. Morphological and phenological description of 38 sweet chestnut cultivars (Castanea sativa Miller) in a contemporary collection. Spanish Journal of Agricultural Research 7: 829-843.

Ganopoulos, I.; Moysiadis, T.; Xanthopoulou, A.; Ganopoulou, M.; Avramidou, E.; Aravanopoulos, F.A.; Tani, E.; Madesis, P.; Tsaftaris, A.; Kazantzis, K. 2015. Diversity of morphophysiological traits in worldwide sweet cherry cultivars of GeneBank collection using multivariate analysis. Scientia Horticulturae 197: 381-391.

Ganopoulos, I.; Moysiadis, T.; Xanthopoulou, A.; Osathanunkul, M.; Madesis, P.; Zambounis, A.; Avramidou, E.; Aravanopoulos, F.A.; Tsaftaris, A.; Sotiropoulos, T. 2016. Morpho-physiological diversity in the collection of sour cherry (Prunus cerasus) cultivars of the Fruit Genebank in Naoussa, Greece using multivariate analysis. Scientia Horticulturae 207: 225-232.

Ganopoulos, I.V.; Kazantzis, K.; Chatzicharisis, I.; Karayiannis, I.; Tsaftaris, A.S. 2011. Genetic diversity, structure and fruit trait associations in Greek sweet cherry cultivars using microsatellite based (SSR/ISSR) and morpho-physiological markers. Euphytica 181: 237-251.

Garkava-Gustavsson, L.; Mujaju, C.; Sehic, J.; Zborowska, A.; Backes, G.M.; Hietaranta, T.; Antonius, K. 2013. Genetic diversity in Swedish and Finnish heirloom apple cultivars revealed with SSR markers. Scientia Horticulturae 162: 43-48.

Gaši, F.; Simon, S.; Pojskic, N.; Kurtovic, M.; Pejic, I. 2010. Genetic assessment of apple germplasm in Bosnia and Herzegovina using microsatellite and morphologic markers. Scientia Horticulturae 126: 164-171.

Gaši, F.; Šimon, S.; Pojski , N.; Kurtovi , M.; Peji , I. 2011. Analysis of morphological variability in Bosnia and Herzegovina's autochthonous apple germplasm. Journal of Food, Agriculture and Environment 9: 444-448.

Gharghani, A.; Zamani, Z.; Talaie, A.; Oraguzie, N.C.; Fatahi, R.; Hajnajari, H.; Wiedow, C.; Gardiner, S.E. 2009. Genetic identity and relationships of Iranian apple (Malus $\times$ domestica Borkh.) cultivars and landraces, wild Malus species and representative old apple cultivars based on simple sequence repeat (SSR) marker analysis. Genetic Resources and Crop Evolution 56: 829-842.

Gupta, P.K.; Balyan, H.S.; Sharma, P.C.; Ramesh, B. 1996. Microsatellites in plants: a new class of molecular markers. Current Science 70: 45-54.

Hamrick, J.L.; Godt, M.J.W. 1996. Effects of life history traits on genetic diversity in plant species. Philosophical Transactions of the Royal Society B: Biological Sciences 351: 1291-1298.
Iezzoni, A.F.; Pritts, M.P. 1991. Applications of principal component analysis to horticultural research. HortScience 26: 334-338.

International Board for Plant Genetic Resources [IBPGR]. 1983. Descriptor List for Apple (Malus). CTA, Wageningen, The Netherlands. (CEC AGPR/IBPGR/82/71, EUR 8354/1).

International Union for the Protection of New Varieties of Plants [UPOV]. 2005. Guidelines for the conduct of tests for distinctness, uniformity and stability. UPOV, Geneva, Switzerland.

Kaiser, H.F. 1958. The varimax criterion for analytic rotation in factor analysis. Psychometrika 23: 187-200.

Kalivas, A.; Ganopoulos, I.; Bosmali, I.; Tsaliki, E.; Osathanunkul, M.; Xanthopoulou, A.; Moysiadis, T.; Avramidou, E.; Grigoriadis, I.; Zambounis, A. 2016. Genetic diversity and structure of tobacco in Greece on the basis of morphological and microsatellite markers. Crop Science 56: 2652-2662.

Khadivi-Khub, A.; Sarooghi, F.; Abbasi, F. 2016. Phenotypic variation of Prunus scoparia germplasm: implications for breeding. Scientia Horticulturae 207: 193-202.

Khadivi-Khub, A.; Zamani, Z.; Fatahi, M.R. 2012. Multivariate analysis of Prunus subgen. Cerasus germplasm in Iran using morphological variables. Genetic Resources and Crop Evolution 59: 909-926.

Kloosterman, A.D.; Budowle, B.; Daselaar, P. 1993. PCRamplification and detection of the human D1S80 VNTR locus. International Journal of Legal Medicine 105: 257-264.

Lassois, L.; Denancé, C.; Ravon, E.; Guyader, A.; Guisnel, R.; Hibrand-Saint-Oyant, L.; Poncet, C.; Lasserre-Zuber, P.; Feugey, L.; Durel, C.-E. 2015. Genetic diversity, population structure, parentage analysis, and construction of core collections in the french apple germplasm based on SSR markers. Plant Molecular Biology Reporter: 1-18.

Liang, W.; Dondini, L.; De Franceschi, P.; Paris, R.; Sansavini, S.; Tartarini, S. 2015. Genetic diversity, population structure and construction of a core collection of apple cultivars from Italian germplasm. Plant Molecular Biology Reporter 33: 458-473.

Madesis, P.; Ganopoulos, I.; Tsaftaris, A. 2013. Microsatellites: evolution and contribution. Microsatellites: Methods and Protocols: 1-13.

Mehmood, A.; Jaskani, M.J.; Khan, I.A.; Ahmad, S.; Ahmad, R.; Luo, S.; Ahmad, N.M. 2014. Genetic diversity of Pakistani guava (Psidium guajava L.) germplasm and its implications for conservation and breeding. Scientia Horticulturae 172: 221232.

Mratinić, E.; Akšić, M.F. 2012. Phenotypic diversity of apple (Malus sp.) germplasm in south Serbia. Brazilian Archives of Biology and Technology 55: 349-358.

Nei, M.; Li, W.-H. 1979. Mathematical model for studying genetic variation in terms of restriction endonucleases. Proceedings of the National Academy of Sciences 76: 5269-5273.

Nikolić, D.; Rakonjac, V.; Milatović, D.; Fotirić, M. 2010. Multivariate analysis of vineyard peach [Prunus persica (L.) Batsch.] germplasm collection. Euphytica 171: 227-234.

Oliveira, E.J.; Dias, N.L.P.; Dantas, J.L.L. 2012. Selection of morpho-agronomic descriptors for characterization of papaya cultivars. Euphytica 185: 253-265. 
Oraguzie, N.C.; Yamamoto, T.; Soejima, J.; Suzuki, T.; Silva, H. 2005. DNA fingerprinting of apple (Malus spp.) rootstocks using simple sequence repeats. Plant Breeding 124: 197-202.

Paetkau, D.; Calvert, W.; Stirling, I.; Strobeck, C. 1995. Microsatellite analysis of population structure in Canadian polar bears. Molecular Ecology 4: 347-354.

Patzak, J.; Paprštein, F.; Henychová, A.; Sedlák, J. 2012. Genetic diversity of Czech apple cultivars inferred from microsatellite markers analysis. Horticultural Science 39: 149-157

Peakall, R.; Smouse, P.E. 2012. GenAlEx 6.5: genetic analysis in Excel: population genetic software for teaching and research an update. Bioinformatics 28: 2537-2539.

Pereira-Lorenzo, S.; Ramos-Cabrer, A.M.; Ascasíbar-Errasti, J.; Piñeiro-Andión, J. 2003. Analysis of apple germplasm in northwestern Spain. Journal of the American Society for Horticultural Science 128: 67-84.

Pina, A.; Urrestarazu, J.; Errea, P. 2014. Analysis of the genetic diversity of local apple cultivars from mountainous areas from Aragon (northeastern Spain). Scientia Horticulturae 174: 1-9.
Rakonjac, V.; Akšić, M.F.; Nikolić, D.; Milatović, D.; Čolić, S. 2010. Morphological characterization of 'Oblačinska'sour cherry by multivariate analysis. Scientia Horticulturae 125: 679-684.

Reig, G.; Blanco, Â.; Castillo, A.M.; Gogorcena, Y.; Moreno, M.Á. 2015. Phenotypic diversity of Spanish apple (Malus $\times$ domestica Borkh) accessions grown at the vulnerable climatic conditions of the Ebro Valley, Spain. Scientia Horticulturae 185: 200-210.

Ruiz, D.; Egea, J. 2008. Phenotypic diversity and relationships of fruit quality traits in apricot (Prunus armeniaca L.) germplasm. Euphytica 163: 143-158.

Somers, K.M. 1986. Multivariate allometry and removal of size with principal components analysis. Systematic Biology 35: 359-368.

Urrestarazu, J.; Miranda, C.; Santesteban, L.G.; Royo, J.B. 2012. Genetic diversity and structure of local apple cultivars from Northeastern Spain assessed by microsatellite markers. Tree Genetics \& Genomes 8: 1163-1180. 